\title{
NUEVA INTERPRETACIÓN DE UNA INSCRIPCIÓN VOTIVA DE MONROY (CÁCERES)
}

\author{
POR \\ JUAN CARLOS OLIVARES PEDREÑO ${ }^{1}$ \\ Universidad de Alicante
}

\section{RESUMEN}

El presente trabajo tiene por objetivo la revisión de lectura de una inscripción que fue hallada durante las excavaciones que se realizaron a finales de la década de los setenta en el foso del castillo de Monroy (Cáceres). Según nuestra interpretación, el teónimo no es un hapax, sino el ya conocido Bandi con un nuevo apelativo.

\section{ABSTRACT}

The present paper offers a new interpretation about the votive altar found in the Monroy castle (Cáceres) three decades ago. We consider that the theonym cited in the inscription is Bandi with an unknown apellative.

PALABRAS CLAVE: Epigrafía votiva, divinidades lusitanas, religión céltica

KEY WORDS: Votive epigraphy, Lusitanian deities, Celtic religion

El altar que nos ocupa fue hallado junto a otras inscripciones de distinta naturaleza cuando se realizaban trabajos de excavación y consolidación en el foso del castillo de Monroy (Cáceres). Estas piezas se encuentran en la actualidad en el interior del mismo. La interpretación de la inscripción que ofrecieron los únicos investigadores que vieron el monumento, J.M. Iglesias y J.L. Sánchez tenía, debido al desgaste del epígrafe, algunos problemas que la fotografía publicada no ayudaba a resolver puesto que no era muy clara en la primera línea, donde constaba el nombre de la divinidad y, además, no mostraba fielmente la forma de la pieza, como hemos podido comprobar recientemente, lo que suponía un obstáculo añadido para su interpretación ${ }^{2}$.

Los citados autores resolvían la lectura del siguiente modo: [R?]udino / Oeno A / dercia A / mbati f(ilia) / u(otum) s(oluit) l(ibens) a(nimo), admitiendo que la lectura del teónimo y su apelativo era hipotética. Asimismo,

\footnotetext{
1 Este trabajo ha sido financiado con una Beca Post-doctoral de Historia concedida por la Fundación Caja Madrid.

2 J.M. Iglesias y J.L. Sánchez, "Nuevas estelas romanas de la provincia de Cáceres", $A E s p A$ 50-51, 1977-78, pp. 423-424, no 3; $A E 1978,393$.
}

resaltaron que el monumento tenía un lóbulo en su parte superior derecha y que habría tenido otro igual en la izquierda que fue eliminado para reutilizar la pieza, como mostraban los restos de argamasa en este lugar. Sin embargo, no parece que tuvieran en cuenta este dato para su lectura de la inscripción (figs. 1 y 2).

Con todo, varios hechos nos llevaron a pensar que la lectura propuesta podía no ser correcta. Tras la observación y el análisis detallado de la inscripción, hemos llegado a la conclusión que hay un espacio mayor entre las letras $i$ y $n$ propuestas por los autores para la primera línea, que el existente entre el resto de las letras y que dicho espacio es similar al que hay en las separaciones entre palabras de otras líneas ${ }^{3}$. Además, se puede observar en ese mismo lugar una interpunción que separa, por tanto, el teónimo de su epíteto, impidiendo la lectura [R?]udino propuesta hasta el momento. Por otra parte, el trazo derecho de la supuesta $u$ del teónimo es, prácticamente, vertical. Parece claro, por tanto, que se trata de los trazos finales de una $n$ que, en consecuencia, muestran el elemento ndi como parte final del teónimo y sugieren el dativo Bandi, correspondiente al dios indígena más difundido de la Península Ibérica y ampliamente testimoniado en toda el área norteña de la provincia de Cáceres ${ }^{4}$.

Esta hipótesis es plausible si tenemos en cuenta que las primeras letras del teónimo habrían ocupado el espacio prominente que ha sido eliminado para la reutilización de la pieza, en el que encajan a la perfección (fig. 3). Por otra parte, el dativo Bandi es el único posible de un teónimo masculino conocido teniendo en cuenta las letras visibles ${ }^{5}$.

\footnotetext{
3 Queremos mostrar nuestro más sincero agradecimiento al propietario del castillo de Monroy, el ilustre pintor D. Pablo Palazuelo y a su familia, que nos dieron todas las facilidades para poder acceder al estudio de la pieza. Igualmente, estamos profundamente en deuda con D. Antonio Naharro, que nos ayudó a localizar la inscripción y a obtener las fotografías.

4 Sobre la distribución territorial de los testimonios de Bandua, uid. J.C. Olivares Pedreño, Los Dioses de la Hispania Céltica. Madrid, 2002, p. 159 con mapa $\mathrm{n}^{\circ} 14$ y p. 165 con tabla $\mathrm{n}^{\circ} 4$.

5 Podría haberse tratado de Munidi si hubiera existido un nexo -ni-, pero en este caso es un teónimo femenino, como sabemos por sus apelativos Eberobrigae Toudopalandigae (F. Fita, "Nuevas inscripciones romana y visigótica de Talaván y Mérida", BRAH 64, 1914, pp. 304-310) y no concordaría con el apelativo masculino [N...]
} 


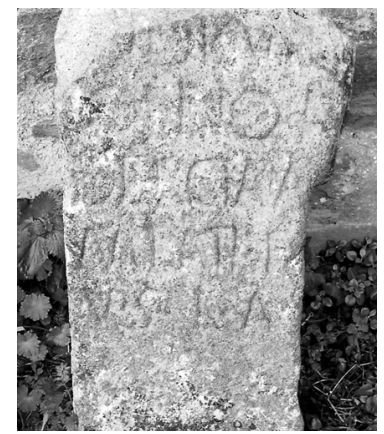

Figura 1.Inscripción votiva del castillo de Monroy (Cáceres).

Más dificultades presenta el apelativo de la divinidad, puesto que no tenemos registrado ninguno que pueda responder a los datos existentes en la inscripción de Monroy. $\mathrm{Su}$ primera letra es, muy probablemente, una $n$, aunque el granito muestra en ese lugar algunas vetas de un color violáceo oscuro que confunden en cierta medida su visión en la fotografía. Los trazos verticales de esta letra tienen, sin embargo, una ligera inclinación, por lo que existe la alternativa, menos probable, de que fuera una $m$. Al final de la línea 1 cabe una o dos letras más que son irreconocibles. En la línea 2, la primera letra podría ser también una $m$, puesto que parece existir parte de su trazo derecho, aunque no es seguro. La parte final del apelativo sí se distingue con claridad y el resto de la inscripción no varía con respecto a su primera publicación, por lo que la interpretación que proponemos es:

$$
\begin{gathered}
\text { [Ba]ndi }[N-- \\
\text {-Joeno A } \\
\text { dercia } A \\
\text { mbatif(ilia) } \\
u(\text { otum) s(oluit) l(ibens) a(nimo) }
\end{gathered}
$$

En consecuencia, con esta ofrenda votiva, se hace más patente la importante difusión del culto a Bandua en toda el área de Cáceres situada al norte de una línea latitudinal que se extiende desde Brozas y Monroy hasta la confluencia de los ríos Tozo y Almonte. Desde esta región, los testimonios del dios llegan hasta las primeras estribaciones del Sistema Central en Extremadura mientras que, en Portugal, continúan más hacia el norte, sobrepasando la Sierra de la Estrella. Precisamente, en los lugares más cercanos de Monroy, donde se hallaron

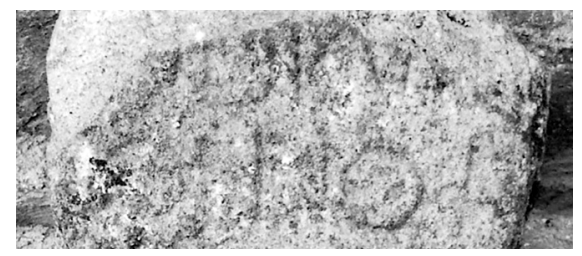

Figura 2. Detalle de las dos primeras líneas de la inscripción.

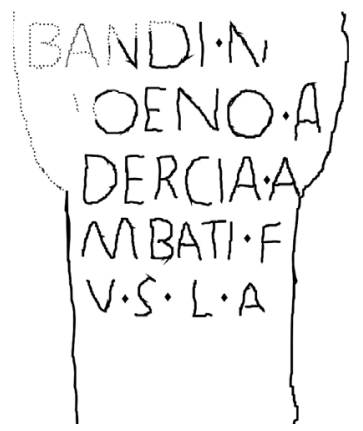

Figura 3. Reconstrucción hipotética parcial de la inscripción.

altares votivos dedicados a Bandua, su culto debió gozar de bastante popularidad y es posible que hubieran existido santuarios bajo su advocación, puesto que en Brozas se descubrieron cuatro aras ofrecidas a Bandi Apuluseaeco ${ }^{6}$ y en la confluencia de los ríos Tozo y Almonte otras tres dedicadas a Bandu Roudaeco ${ }^{7}$.

Como es habitual en las ofrendas a este dios, el dedicante de la inscripción de Monroy tiene nombre y filiación autóctona pero, lo que no es tan frecuente, se trata de una mujer ${ }^{8}$. Por lo demás, no hallamos datos en esta inscripción que nos aporten algún conocimiento nuevo sobre la naturaleza de la deidad, pero sí que podemos insistir en el importante lugar que ocupó en la cultura lusitana, puesto que sus altares rebasan ampliamente el medio centenar.

En cuanto al nombre de la dedicante, Adercia, no aparece en ningún otro testimonio, pero sí en masculino en Casas de Millán (Cáceres), es decir, a unos 20 km en línea recta desde Monroy. En esta pieza, un individuo de nombre Cainolus, Aderci filius, hizo un voto, precisamente, a otra deidad indígena ${ }^{9}$. En cuanto al nombre del padre de la oferente, Ambatus, está ampliamente registrado en el occidente de la Península Ibérica ${ }^{10}$.

Recibido el 16-06-06

Aceptado el 10-09-06

6 En ellas consta el mismo apelativo, pero con algunas variantes: Apolosego (CIL II 740), Apuluseaeco (CIL II 741; J. Salas, J. Esteban y G. Rueda, "Bandia Apolosegus, una divinidad de culto local en la zona de Brozas, Cáceres. Nuevas aportaciones epigráficas", HAnt. 13, 1986-1989, pp. 7-8, no 1) y Apolluseaeco (Salas et al., ibid., p. 10-11, n²).

7 En este lugar se hallaron tres inscripciones dedicadas a Bandu Roudaeco (M. Beltrán, "Aportaciones a la epigrafía y arqueología romana de Cáceres”, Caesaraugusta 39-40, 1975 76, pp. 87-93, no 59, 60 y 61). Con este apelativo se halló otra inscripción más al este, en Madroñera (Ibid., $\mathrm{n}^{\circ}$ 64).

8 J.C. Olivares Pedreño, op. cit. en nota 4, p. 160 ss.

9 El nombre de la divinidad es Moricilo (M. Beltrán, op. cit. en nota 7, pp. 78-79; $A E 1977,424)$.

10 J.M. Abascal Palazón, Los nombres personales en las inscripciones latinas de Hispania. Murcia, 1994, pp. 269 ss. 